\title{
CONCENTRAÇÃO E PODER DE MERCADO NA DISTRIBUIÇÃO DE ETANOL COMBUSTIIVEL: ANÁLISE SOB A ÓTICA DA NOVA ORGANIZAÇÃO INDUSTRIAL EMPÍRICA
}

\author{
Paula Rubia Simões Beiral * \\ Márcia Azanha Ferraz Dias de Moraes ${ }^{\dagger}$ \\ Mirian Rumenos Piedade Bacchi ${ }^{\ddagger}$
}

\begin{abstract}
Resumo
A reorganização do mercado de distribuição de combustíveis levanta a questão da existência de poder de mercado nesse setor. O presente trabalho utiliza a ferramenta da Nova Organização Industrial Empírica (New Empirical Industrial Organization - NEIO) para analisar a existência de poder de mercado no setor de distribuição. Apoia-se nos trabalhos de Bresnahan (1982) e Bresnahan (1989) para a consideração de métodos de identificação do parâmetro de conduta e procura verificar se a metodologia é adequada ao mercado em questão. Conclui-se que os distribuidores não exercem efetivamente poder de mercado. Os valores dos parâmetros de conduta estimados mostram que a conduta se aproximou mais da concorrência perfeita que do monopólio.
\end{abstract}

Palavras-chave: Etanol; NEIO; Organização Industrial; Poder de Mercado.

\begin{abstract}
The reorganization of fuel distribution market raises questions regarding the existence of market power in the sector. Tools of New Empirical Industrial Organization were used to analyze existence of market power in the distribution sector. Based on the studies of Bresnahan (1982) and Bresnahan (1989), an analysis of identification methods for conduct parameters was carried out in order to determine whether the methodology is appropriate for the market in question. We concluded that distributors do not effectively practice market power. Estimated values for conduct parameters show this market approaches perfect competition not monopoly.
\end{abstract}

Keywords: Ethanol; NEIO; Industrial Organization; Market power.

JEL classification: L11

\footnotetext{
* ESALQ/USP. E-mail: paula.beiral@ijsn.es.gov.br

† ESALQ/USP. E-mail: mafdmora@esalq.usp.br

‡ ESALQ/USP. E-mail: mrpbacch@esalq.usp.br
} 


\section{Introdução}

O Brasil vem experimentando um aumento da participação do etanol combustível nas vendas totais de combustíveis nos anos recentes. Uma análise dos dados das vendas de etanol hidratado combustível da Agência Nacional do Petróleo, Gás Natural e Biocombustíveis (ANP) confirma a afirmação: no ano 2000 , as distribuidoras venderam cerca de $4.603 .588 \mathrm{~m}^{3}$ de álcool hidratado, passando para cerca de $16.470 .948 \mathrm{~m}^{3}$ em 2009. Já as vendas de gasolina C foram de cerca de $22.630 .192 \mathrm{~m}^{3}$ em 2000 e cerca de $25.409 .090 \mathrm{~m}^{3}$ em $2009 .^{1}$ Comparando as vendas dos dois tipos de combustíveis, percebe-se o salto no consumo de etanol hidratado comparativamente ao consumo de gasolina C.

Carros movidos unicamente a etanol já existiam no Brasil desde o início da década de 1980, em decorrência do Programa Nacional do Álcool (Proálcool). A introdução dos carros biocombustíveis em 2003, conhecidos como flex-fuel, trouxe mudanças tecnológicas substanciais, e em 2008 nove em cada dez carros novos produzidos no Brasil eram do tipo flex (Salvo \& Huse 2011).

Estimativas da Empresa de Pesquisa Energética (EPE) projetam um aumento de $150 \%$ na demanda total por etanol brasileiro no período $2008-2017 .^{2}$

Além da crescente demanda por etanol hidratado, outra fonte do aumento da demanda por etanol decorre do uso de anidro. A ANP especifica que a comercialização do etanol etílico se dê de duas formas: Etanol Etílico Anidro Combustível (AEAC) e Etanol Etílico Hidratado Combustível (AEHC). O primeiro é desidratado, tem teor alcoólico mínimo de $99,3^{\circ}$ INPM e participa da mistura com a gasolina A (100\% pura) formando a gasolina C. Atualmente, o volume de etanol anidro na gasolina varia entre $18 \%$ e $25 \%$ por força da legislação. Já o hidratado tem teor alcoólico entre $92,6^{\circ}$ e 93, $8^{\circ}$ INPM, sendo usado puro como combustível. Na safra 09/10, o Brasil produziu 25,7 milhões $\mathrm{m}^{3}$ de etanol, sendo 18,8 milhões $\mathrm{m}^{3}$ de etanol hidratado, e 6,9 milhões $\mathrm{m}^{3}$ de etanol anidro. ${ }^{3}$

Dado esse aumento na demanda de etanol combustível nacional e na perspectiva de uso em outros países, muitas oportunidades de negócio emergiram no país. No elo nacional da distribuição de combustíveis, no início do ano de 2009, um conjunto de alguns grandes grupos (BR Distribuidora, Ipiranga, Texado, Shell e Esso [do grupo Cosan e Alesat]) representava cerca de $80 \%$ do mercado de distrbuição de combustíveis automotivos no Brasil.

A emergência de um processo de novos investimentos e o aumento da concentração de mercado levam ao problema investigado no presente trabalho: busca-se verificar a existência e o grau de poder de mercado no segmento de distribuição de combustíveis. Para isso, usa-se a abordagem da Nova Organização Industrial Empírica (NEIO), que procura aferir o grau de poder de mercado através da identificação de um parâmetro de conduta, com modelos que assumem custos marginais não observáveis (Bresnahan 1989).

O problema da concentração de mercado surge devido ao fato de tal concentração possibilitar o exercício do poder de mercado, com consequente perda

\footnotetext{
${ }^{1}$ Dados disponíveis em: http : / /www. anp.gov.br $/$ ?pg=23307\&m=\&t 1=\&t2=\&t3=\& $\mathrm{t} 4=\& \mathrm{ar}=\& \mathrm{ps}=\& \mathrm{cachebust}=1274463415336$.

${ }^{2}$ Disponível em: http://www.epe.gov.br/imprensa/PressReleases/20080924_1. pdf.

${ }^{3}$ Ministério da Agricultura Pecuária e Abastecimento - MAPA. Disponível em: http: / / www . agricultura.gov.br/pls/portal / docs / PAGE / MAPA/ESTAT IST ICAS/PRODUCA0/ 06\discretionary-PR0D.\%20BR\%20ETANOL_0.PDF.
} 
de bem-estar social. "Poder de mercado é a habilidade de aumentar o preço lucrativamente acima do custo marginal" (Church \& Ware 2000).

Daskin (1991) mostra que a decisão das firmas (com poder de mercado) em manter preço acima do custo marginal reduz o excedente do consumidor e aumenta o lucro da firma em relação a seus níveis em um mercado competitivo. A diferença entre o aumento do excedente do produtor e a redução do excedente do consumidor representa a perda de bem-estar social.

Assim, ressalta-se a importância de mensurar o poder de mercado no elo da distribuição de etanol no Brasil, principalmente quando se considera que a demanda por etanol combustível está em ascendência desde a implantação e disseminação do uso de carros flex-fuel no país.

Além do foco de investigar a existência de poder de mercado (em decorrência de seus impactos negativos sobre o bem-estar social), o interesse do presente estudo está no fato de que “(...) a consideração dos modelos NEIO no contexto das economias em desenvolvimento tem recebido pouca atenção na literatura",4 segundo Zeidan \& Resende (2009).

Dessa forma, busca-se trabalhar duas questões: a investigação da existência de poder de mercado no elo da distribuição de etanol combustível hidratado; e a aplicação do modelo da NEIO, para a identificação de um parâmetro de conduta, testando sua eficácia no presente contexto. Ressalta-se, no entanto, que o modelo NEIO utilizado, baseado em Bresnahan (1982), é estático. Steen \& Salvanes (1999) consideram uma versão dinâmica para o modelo NEIO, a qual Zeidan \& Resende (2009) aplicaram para o mercado de cimento.

A referência principal, no caso da aplicação de modelos da NEIO, são os trabalhos de Bresnahan (1982) e sua resenha clássica de 1989. E no caso do teste da eficácia para o mercado de distribuição de etanol combustível, este trabalho baseia-se em Genesove \& Mullin (1998), que testaram a metodologia NEIO para o mercado de açúcar dos Estados Unidos para o período entre o fim do século XIX e início do século XX, partindo de dados observáveis de custo marginal. Esses autores obtiveram estimativas alternativas de um parâmetro de conduta de mercado (denominado "medida de conduta direta") com o qual testaram a eficácia da metodologia NEIO em estimar conduta de mercado. Assim, baseado no referido trabalho, pretende-se desenvolver uma estimativa de custos marginais para o elo da distribuição de etanol, para estimar-se um parâmetro de conduta alternativo (inferência direta do parâmetro de conduta que utilize informações de custos), que possa ser comparado aos resultados encontrados pela metodologia NEIO (que não utiliza informações completas de custo). Entretanto, ressalta-se que o presente trabalho, apesar de possuir uma maior certeza sobre custos da distribuição de etanol e, portanto, uma estimativa confiável dos custos marginais, possui um escopo mais limitado que o de Genesove \& Mullin (1998). Isso porque, mesmo conseguindo construir um parâmetro de conduta de inferência direta (utilizado comparativamente ao parâmetro de conduta de inferência indireta da NEIO), não emprega uma análise de robustez como a de Genesove \& Mullin (1998), que utilizaram quatro formas funcionais de demanda.

O presente trabalho procura caracterizar a estrutura da distribuição do etanol hidratado, bem como verificar o desempenho do mesmo para o estado de São Paulo, ${ }^{5}$ que é o maior estado produtor e consumidor. Quando se vis-

\footnotetext{
${ }^{4}$ Livre tradução.

${ }^{5}$ Deve-se ressaltar que a metodologia da NEIO não se preocupa com a definição do mercado
} 
lumbra a produção por estado da federação, São Paulo responde por cerca de $68 \%$ da produção da região Centro-Sul, e por $59,4 \%$ das usinas dessa região. Assim, é justificável a análise focada no estado de São Paulo, como segue no presente caso.

Na seção 2, discutem-se alguns indicadores de concentração de mercado para o segmento de distribuição de etanol. Segue-se a descrição da metodologia, com uma pequena introdução dando uma visão global do trabalho, na seção 3. Ela se divide em subseções em que se discutem a metodologia específica à construção do custo marginal e a metodologia para estimação da elasticidade da demanda de etanol ao distribuidor, além do parâmetro de conduta da NEIO. Na seção 4 apresentam-se os resultados. Ao final, apresentam-se as conclusões, seguidas da literatura consultada e Apêndices.

\section{Indicadores de concentração da distribuição de etanol}

A Tabela 1 traz indicadores da concentração de mercado do elo da distribuição de etanol para o Brasil, dados pela participação das distribuidoras nas vendas nacionais de álcool etílico hidratado, desde o ano 2000 até 2009. Os indicadores são o CR4 (a participação das quatro maiores distribuidoras), o CR10 (participação das 10 maiores), o HHI (Herfindahl-Hirschman Index) e o "Número Equivalente". 6

Tabela 1: Índices de concentração do mercado de distribuição de combustíveis

\begin{tabular}{cccccc}
\hline ANO & $\mathrm{n}^{\text {o distribuidoras }}$ & CR4 & CR10 & HHI & número equivalente \\
\hline 2000 & 165 & $40.07 \%$ & $78.73 \%$ & 573,15 & 17 \\
2001 & 157 & $40.82 \%$ & $80.05 \%$ & 590,33 & 17 \\
2002 & 166 & $65.24 \%$ & $89.43 \%$ & 1363,77 & 7 \\
2003 & 159 & $40.26 \%$ & $79.55 \%$ & 617,49 & 16 \\
2004 & 170 & $41.20 \%$ & $75.90 \%$ & 596,28 & 17 \\
2005 & 163 & $48.54 \%$ & $79.25 \%$ & 745,73 & 13 \\
2006 & 154 & $41.46 \%$ & $81.23 \%$ & 624,47 & 16 \\
2007 & 159 & $47.81 \%$ & $83.61 \%$ & 743,8 & 13 \\
2008 & 157 & $49.93 \%$ & $82.79 \%$ & 795,49 & 13 \\
2009 & 154 & $57.41 \%$ & $73.92 \%$ & 1047,59 & 10 \\
\hline
\end{tabular}

Fonte: Elaboração própria, com dados de participação da ANP.

relevante. Aqui, toma-se o estado de São Paulo como uma proxy para o Brasil. Isso é possível, dado que São Paulo é tido como representante da região Centro-Sul (maior produtora de etanol do país). Os estados de São Paulo e Paraná representam juntos mais de $70 \%$ da produção da região Centro-Sul. Dessa forma, sabe-se que os preços desse estado e do país convergem, permitindo o uso de São Paulo como representativo da produção do país.

${ }^{6} \mathrm{O} \mathrm{CR}(i)$ dá a Razão de Concentração de mercado das iésimas maiores firmas, calculado somando-se a participação das $i$ maiores firmas do mercado. Quanto maior o CR, maior a concentração. Já o HHI calcula concentração do mercado como um todo e não apenas a participação das maiores, e capta também a desigualdade. Para calcular o HHI toma-se a participação (s) de cada firma $i$ elevada ao quadrado e somadas ao final a participação das $N$ firmas do mercado: $H H I=\sum_{i=1}^{N} S_{i}^{2}$. A classificação da concentração de mercado baseada no HHI, definida pela Secretaria de Acompanhamento Econômico (SEAE), é descrita em: http://www1. seae.fazenda gov.br/littera/pdf/08012009455200829.pdf. Assim, um HHI menor que 1.000 indica baixa concentração, de 1.000 a 1.800 indica concentração moderada e acima de 1.800 indica alta concentração. O "número equivalente" corresponde ao número de firmas de igual tamanho, necessário para se obter a mesma concentração de mercado. 
Não há uma tendência clara da evolução do número de distribuidoras e concentração no período analisado. O CR4 atingiu seu maior valor em 2002, dado, sobretudo, pela maior participação da BR distribuidora nesse ano. $\mathrm{O}$ HHI ultrapassou os mil pontos em 2002, mas como no resto do período esteve inferior a esse valor, pode ser considerado um mercado de baixa concentração. O número equivalente que era de 17 nos anos 2000 e 2001 cai para 7 em 2002 (indicando aumento da concentração), mas volta a crescer no ano seguinte, atingindo 17, novamente, em 2004. Oscila nos anos seguintes, atingindo o valor de 10 em 2009. Entretanto, apesar de ter caído, indicando aumento na concentração, o valor de 10 ainda pode ser considerado alto, pois, segundo Farina et al. (2010), uma dezena de competidores com mesmo tamanho pode gerar forte competição pela compra da matéria-prima ou pela venda para os postos.

O CR4 no ano de 2009 foi de aproximadamente $57 \%$, ultrapassando todos os anos anteriores exceto 2002, ratificando a aparente ascendência da concentração em anos recentes: quase 60\% do mercado de distribuição, em 2009, pertencia às quatro maiores distribuidoras. Entende-se assim, segundo Neves \& Conejero (2010) que o mercado de distribuição é caracterizado como um oligopólio com franja competitiva, ou oligopsônio quando se visualiza a compra de etanol pelas distribuidoras.

\section{Metodologia}

Nesta seção, descreve-se a metodologia do trabalho: na subseção 3.1 discutese o problema de identificação do parâmetro de conduta de inferência indireta, a partir do modelo estrutural, seguido da discussão sucinta da inferência direta a partir do modelo de Genesove \& Mullin (1998) e da comparação entre os parâmetros de inferência direta e indireta. A seção 3.2 aborda o método de estimativa do custo marginal da distribuição, e a seguinte (3.3), o método para estimar a elasticidade da demanda e o parâmetro de conduta da NEIO.

\subsection{Inferência indireta do parâmetro de conduta - NEIO}

Como visto, a teoria que suporta a presente pesquisa é a Nova Organização Industrial Empírica (NEIO). A discussão clássica da metodologia em questão está em Bresnahan $(1982,1989)$.

Conforme relatado por Bresnahan (1989), o modelo estilizado possui três conjuntos de parâmetros: custos, demanda e conduta da firma. Preço e quantidade são variáveis endógenas, portanto, observáveis, enquanto custos marginais não são diretamente observáveis nos modelos NEIO.

A curva de demanda inversa pode ser genericamente descrita como:

$$
P_{t}=D\left(Q_{t}, Y_{t}, \delta, \varepsilon_{d t}\right)
$$

Onde $Q_{t}$ é o produto total, $Y_{t}$ representa as variáveis que deslocam a curva de demanda (como renda, sazonalidade e preço de bens substitutos, ou seja, elementos exógenos), $\delta$ são parâmetros desconhecidos da função demanda a serem estimados e $\varepsilon_{d t}$ é o termo de erro.

Da mesma forma, designa-se a função custo do modelo estilizado:

$$
C_{i t}=C\left(Q_{i t}, W_{i t}, \Gamma, \varepsilon_{c i t}\right)
$$


Sendo $Q_{i t}$ o produto da firma, $i, W_{i t}$ as variáveis deslocadoras da função custo (como preço dos fatores, sazonalidade, tecnologia), $\Gamma$ os parâmetros desconhecidos da função custo, a serem estimados, e $\varepsilon_{c i t}$ são os termos de erros.

Bresnahan (1989) inclui uma variável $Z_{i t}$ na curva de custo e a designa como sendo a variável deslocadora da função custo, enquanto $W_{i t}$ seria o vetor de preço de fatores. Portanto, na versão de Bresnahan (1989) do modelo estilizado a curva de custo é escrita como $C_{i t}=C\left(Q_{i t}, W_{i t}, Z_{i t}, \Gamma, \varepsilon_{c i t}\right)$. Entretanto, no modelo apresentado acima, designa-se apenas a variável $W_{i t}$ que inclui todas as variáveis deslocadoras da curva de custo, inclusive preços de fatores.

O custo marginal será então:

$$
M C=C_{1}\left(Q_{i t}, W_{i t}, \Gamma, \varepsilon_{c i t}\right)
$$

Bresnahan (1989) ressalta que fora do modelo de concorrência perfeita, as firmas não possuem curvas de oferta (uma solução preço igual ao custo marginal em função da quantidade). Portanto, fala-se em relações de oferta ao invés de curvas de oferta.

Os lucros da firma $i\left(\pi_{i}\right)$ são definidos pela receita total subtraída dos custos totais:

$$
\pi_{i t}=D\left(Q_{t}, Y_{t}, \delta, \varepsilon_{d t}\right) Q_{i t}-C\left(Q_{i t}, W_{i t}, \Gamma, \varepsilon_{c i t}\right)
$$

Da condição de primeira ordem da maximização, o custo marginal igualase à receita marginal, onde esta última é designada como:

$$
\operatorname{MR}\left(Q_{t}, Y_{t}, \delta, \Theta_{i}\right)=P+\frac{d P}{d Q} Q_{i t} \Theta_{i t}
$$

Sendo $\frac{d P}{d Q}$ a inclinação da curva de demanda e $\Theta_{i t}$ o parâmetro que mede a conduta. Se $\Theta_{i t}$ for zero, a firma $i$ é tomadora de preços e a receita marginal iguala-se ao preço. Quando $\Theta_{i t}$ for igual a um, tem-se o monopólio.

Fazendo a receita marginal (5) igual ao custo marginal (3), e modificando algebricamente, tem-se a relação de oferta da firma $i$ :

$$
P_{t}=C_{1}\left(Q_{i t}, W_{i t}, \Gamma, \varepsilon_{c i t}\right)-\frac{d P}{d Q} Q_{i t} \Theta_{i t}
$$

Subtraindo $C_{1}\left(Q_{i t}, W_{i t}, \Gamma, \varepsilon_{c i t}\right)$ nos dois lados, dividindo por $P_{t}$, em seguida multiplicando e dividindo por $Q_{t}$ e rearranjando:

$$
\frac{P_{t}-C_{1}\left(Q_{i t}, W_{i t}, \Gamma, \varepsilon_{c i t}\right)}{P_{t}}=-\frac{d P}{d Q} \frac{Q_{t}}{P_{t}} \frac{Q_{i t}}{Q_{t}} \Theta_{i t}
$$

Onde $-\frac{d P}{d Q} \frac{Q_{t}}{P_{t}}$ é o inverso da elasticidade-preço da demanda do mercado, ou seja, $\frac{1}{\varepsilon}$ e $\frac{Q_{i t}}{Q_{i}}=s_{i}$ é a participação ou o 'market share' da firma $i$ no mercado.

Substituindo $s_{i}$ e $\frac{1}{\varepsilon}$ :

$$
\frac{P_{t}-C_{1}\left(Q_{i t}, W_{i t}, \Gamma, \varepsilon_{c i t}\right)}{P_{t}}=\frac{s_{i} \Theta_{i t}}{\varepsilon}
$$

Na solução de equilíbrio, em uma indústria com n firmas, haverá uma relação de oferta como (7) para cada firma, e o equilíbrio da indústria é determinado pela solução simultânea das n relações de oferta com a função demanda e da identidade $Q_{t}=\sum Q_{i t}$. 
Segundo Bresnahan (1989), desde que se trate de um caso de produto único, $Q_{t}=\sum Q_{i t}$ é bem definido. Em outras palavras, o equilíbrio é determinado pela interação entre todos os produtores e consumidores. Assim, há um conjunto de $n+2$ quações que determinam $n+2$ variáveis, as quais são o produto de cada firma, $Q_{i t}$, o produto da indústria, $Q_{t}$, e o preço, $P_{t}$. Essas são variáveis endógenas, como relatado. As variáveis exógenas, ou prédeterminadas, são os fatores deslocadores de demanda, $Y_{t}$, ou de oferta, $W_{i t}$. Assim, busca-se derivar estimativas para a conduta da firm $i, \Theta_{i t}$, e os parâmetros de demanda, $\delta$, e oferta, $\Gamma$.

Havendo informação apenas no nível de indústria (o agregado das firmas individuais), não se pode determinar a conduta de cada firma $i$, mas sim a conduta média do mercado, $\Theta$. Assim, a relação de oferta da indústria é:

$$
P_{t}=C_{1}\left(Q_{t}, W_{t}, \Gamma, \varepsilon_{c t}\right)-\frac{d P}{d Q} Q_{t} \Theta_{t}
$$

Em que $C_{1}(\cdot)$ é o custo marginal da indústria, que depende das variáveis deslocadoras da função custo $(W)$ e dos parâmetros $(\Gamma)$. Nota-se também a dependência da inclinação da curva de demanda em relação às variáveis deslocadoras da curva de demanda $(Y)$ e dos parâmetros $(\delta)$.

A questão que surge é se a relação de oferta e a curva de demanda são identificadas pelos dados de quantidade $Q$ e de preço $P$. Ou seja, se $Q$ e $P$ são pontos de equilíbrio simultaneamente determinados pela interação entre produtores e consumidores. Ou como colocado por Bresnahan (1982), a questão formal é se o parâmetro de conduta é identificado pela demanda e oferta (modelo estrutural), ou seja, se modelos competitivos e monopólicos seriam observavelmente distintos.

Para iniciar a discussão sobre a distinção entre o caso de competição e monopólio, ou seja, a identificação do parâmetro de conduta de inferência indireta pelo modelo estrutural supõe-se, inicialmente, que a renda seja a variável deslocadora da curva de demanda, e que não haja variáveis deslocadoras da relação de oferta: se o bem é normal, aumentos na renda deslocam a curva de demanda para cima e para direita, sobre a curva de oferta, gerando uma série de valores de equilíbrio $\left(Q_{1}, P_{1}\right),\left(Q_{2}, P_{2}\right)$ e assim por diante. Dessa forma, a variável deslocadora da demanda (no caso a renda) permite a identificação de parâmetros da oferta.

Analogamente, uma mudança em uma variável deslocadora da oferta faz o custo marginal variar, deslocando a oferta sobre a curva de demanda, gerando pontos de equilíbrio estáticos, que permitem determinar os parâmetros subjacentes à curva de demanda. Quer dizer, para a identificação da curva de demanda (ou da relação de oferta), é necessário que haja variáveis exógenas na relação de oferta (ou na curva de demanda) que não estejam na curva de demanda (ou na relação de oferta). A condição de ordem para a identificação do modelo estabelece que o número de variáveis exógenas excluídas da equação seja maior ou igual ao número de variáveis endógenas menos um (Church \& Ware 2000). Como há duas variáveis endógenas, $Q$ e $P$, e ambas são equações, a função demanda (ou de oferta) será identificada se houver uma variável exógena na oferta (ou na demanda) que não esteja na função demanda (ou na de oferta).

A maneira como os preços (e/ou quantidades) respondem aos choques de demanda ou de custos caracteriza a conduta de mercado. Por isso a NEIO infere conduta e parâmetros de custo desconhecidos a partir da resposta dos 
preços às variações na demanda e de componentes do custo. Entretanto, até aqui apenas identificaram-se as curvas de demanda e oferta, mas não o grau de poder de mercado (Bresnahan 1982).

Supondo uma curva de demanda inversa da seguinte forma:

$$
P=\delta_{0}+\delta_{1} Q+\delta_{2} Y_{1}+\delta_{3} Y_{1} Q+\delta_{4} Y_{2}
$$

Em que $\delta$ 's são os parâmetros de demanda a serem estimados; $Y_{1}$ e $Y_{2}$ são as variáveis exógenas (deslocadoras da curva de demanda). Aqui, a inclinação da demanda seria:

$$
\frac{d P}{d Q}=\delta_{1}+\delta_{3} Y_{1}
$$

Nesse caso, a interação entre a variável exógena e a quantidade, $Y_{1} Q$, faz com que mudanças na variável exógena promovam uma rotação da curva de demanda (além do deslocamento) permitindo-se determinar o parâmetro de conduta, em casos em que o custo marginal não é constante. ${ }^{7}$

No exemplo acima, em que o custo marginal não é constante, para se identificar a conduta, é importante que quando a variável exógena mudar, a curva da demanda sofra também rotação, e não apenas deslocamento. Isso porque, com a rotação da curva de demanda, a receita marginal irá variar, e se a firma possui poder de mercado, sua receita marginal sendo $M R\left(Q_{t}, Y_{t}, \delta, \Theta_{t}\right)=$ $P+\frac{d P}{d Q} Q_{i t} \Theta_{i t}$, os preços e quantidades reagirão de modo diferente de como reagiriam para uma firma em concorrência perfeita. Dessa forma, o parâmetro de conduta é identificado.

Entretanto, quando o custo marginal é constante, $C_{1}=\tau_{0}+\tau_{1} W$, é possível identificar o parâmetro de conduta sem a necessidade de inserção de variáveis de interação do tipo $Y_{1} Q$ na curva de demanda. Isso porque a resposta de uma firma competitiva e uma firma não competitiva será sempre diferente, sobre custo marginal constante. Por exemplo, se uma expansão na renda deslocar a curva de demanda para fora, uma firma competitiva expande sua produção até que o preço volte a se igualar ao custo marginal. Mas a firma não competitiva poderia expandir apenas até o custo marginal se igualar à receita marginal.

\section{Inferência direta do parâmetro de conduta}

Seguindo o modelo aplicado por Genesove \& Mullin (1998), o presente trabalho empenha-se em construir a "medida de conduta direta" a partir da equação 8

$$
\Theta=\frac{P-c}{P} \eta(P) \equiv L \eta
$$

Onde $P$ é o preço de mercado, $C$ é o custo marginal e $\eta(P)$ é a elasticidade da demanda.

\footnotetext{
${ }^{7}$ Church \& Ware (2000) apresentam também a análise gráfica dos casos apresentados.

${ }^{8}$ Dada uma especificação geral para a curva de demanda $Q=\beta(\alpha-P)$, que colocada em termos de $P$ fica: $P=\alpha-\frac{Q}{\beta}$. Tem-se $P^{\prime}(Q)=-\frac{1}{\beta} \equiv-\frac{d P}{d Q}$. Substituindo $P^{\prime}(Q)$ em $P+\Theta Q P^{\prime}(Q)=c$, tem-se: $P-\Theta Q \frac{d P}{d Q}=c$, e rearranjando: $(P-c) \frac{d Q}{d P} \frac{1}{Q}=\Theta$. Multiplicando e dividindo por $P$ :

$\frac{P-c}{P} \frac{d Q}{d P} \frac{P}{Q}=\Theta$, onde $\frac{d Q}{d P} \frac{P}{Q} \equiv \eta(P)$ é a elasticidade-preço da demanda. Substituindo: $\Theta=$ $\frac{P-C}{P} \eta(P) \equiv L \eta$
} 
Posteriormente, estima-se um parâmetro de conduta de mercado de inferência indireta, pela técnica da Nova Organização Industrial Empírica (NEIO), apresentada anteriormente, e comparam-se as duas estimativas.

Conforme discutido, a técnica da NEIO consiste em estimar um modelo de equações simultâneas, composto por uma equação de demanda e uma relação de oferta, que simultaneamente determinam preço e quantidade de equilíbrio. Para aplicar esta técnica, então, surge a necessidade de um modelo que considere esta simultaneidade na estimação das curvas, e pode ser solucionado a partir da utilização do método de Mínimos Quadrados em Dois Estágios (MQ2E), considerando-se a endogeneidade de variável explicativa.

Assim, o presente trabalho parte da estimação da elasticidade da demanda, $\eta(P)$, e a estimação de uma série de custo marginal, que juntamente aos preços de mercado formarão o parâmetro de conduta de inferência direta, ${ }^{9}$ dada pela equação (11). Isto feito, aplica-se a técnica de estimação de conduta da NEIO (parâmetro de inferência indireta, o qual não usa informações de custos completas) por meio do modelo estrutural, que parte da estimação da demanda, seguida da construção e estimação da relação de oferta, a qual inclui a estimação do parâmetro de conduta. Para tal, emprega-se a técnica de estimação de dois estágios (MQ2E), utilizando-se do pacote estatístico RATS - Regression Analysis of Time Series.

Com o parâmetro de conduta de inferência direta (dada por $L \eta-c o m$ informações de custo) e o parâmetro de conduta estimado via metodologia NEIO (modelo estrutural - sem informações completas de custo), o trabalho conclui sobre a existência ou não de poder de mercado e sobre a eficiência da metodologia NEIO em estimar conduta de mercado para o elo da distribuição de etanol para o estado de São Paulo. ${ }^{10}$

\subsection{Metodologia para o cálculo do custo marginal da distribuição de etanol}

Baseado nas estimativas dos custos de aquisição das companhias distribuidoras de combustíveis divulgados pelo Sindicato do Comércio Varejista de Derivados de Petróleo do Estado de São Paulo (Sincopetro), que produz tabelas de custos mensais, com base nos dados divulgados pela ANP e pelas distribuidoras de combustíveis (líquidos e gasosos) que atuam no Brasil, ${ }^{11}$ percebe-se que cerca de $70 \%$ do custo marginal da distribuidora de etanol provem do preço de etanol ao produtor, e o restante refere-se aos impostos (PIS/COFINS e ICMS) e frete. Ressalta-se que a distribuição do etanol constitui, de forma simplificada, no processo de deslocamento dos caminhões das distribuidoras até as usinas para a busca do etanol, e o deslocamento do mesmo até os postos. Em relação aos custos com a mão de obra, estes não entram no custo marginal uma vez que se pode considerá-los como custos fixos. Para isso, assume-se que a formação dos salários não é correlacionada com a produção, sendo formados exogenamente, no mercado de trabalho.

Sobre os impostos, produtores e distribuidoras de etanol hidratado reco-

\footnotetext{
${ }^{9} \mathrm{Ou}$ seja, o parâmetro de conduta obtido por meio de informações de custos conhecidas

${ }^{10}$ Mais uma vez, destaca-se que o estado de São Paulo é tomado como proxy para o Brasil.

${ }^{11}$ Tabela disponível em: http://WWW.sincopetro.org.br/conteudo.asp? $\mathrm{xmenu}=110$.
} 
lhem ICMS ${ }^{12}$ (estadual) e PIS/COFINS ${ }^{13}$ (federal) sobre o etanol. Quanto ao frete, refere-se à distância da usina à base de distribuição, e a posterior entrega nos postos revendedores (Farina et al. 2010).

Assim, o presente trabalho estima uma série de tempo de custo marginal da distribuição de etanol hidratado, para o período de janeiro de 2003 a maio de 2010, da maneira descrita a seguir.

O custo marginal é dado pela soma dos valores de ICMS (a alíquota de ICMS que incide sobre o preço de distribuidor), com valores de PIS/COFINS (a alíquota do PIS/COFINS sobre este mesmo preço, até setembro de 2008, passando a ser um valor fixo a partir de outubro do mesmo ano), mais o valor médio do frete, e o valor pago pelo distribuidor na aquisição do etanol do produtor. Assim o custo marginal é definido pela equação:

$$
c m g=I C M S(\text { Pdist })+\text { PIS } / \text { CONFIS }(\text { Pdist })+\text { Frete }+ \text { Pprod }
$$

Onde Pdist é o preço ao distribuidor de etanol hidratado, e Pprod é o preço de etanol hidratado ao produtor, ${ }^{14}$ para o estado de São Paulo.

Baseado nas informações da Sincopetro, que divulga semanalmente ${ }^{15} \mathrm{um}$ custo de frete estimado entre as usinas e distribuidoras, ${ }^{16}$ o presente trabalho utiliza o valor médio de $\mathrm{R} \$ 0,05 / 1$ para o custo do frete.

Após estimar-se a série de $\mathrm{cmg}$, para o referido período (janeiro de 2003 a maio de 2010), e com a elasticidade da demanda estimada, e considerandose os dados de preço de distribuidor, Pdist, computa-se o Índice de Lerner elasticidade-ajustado no tempo, dado por:

$$
\Theta=\eta_{P d i s t} \frac{P d i s t-c m g}{P d i s t} \equiv L \eta_{\text {dist }}
$$

Após isso estima-se a média para o período da pesquisa, ou seja, a medida de conduta direta, que será usada para comparar a estimativa do parâmetro de conduta da NEIO.

\subsection{Metodologia para o cálculo da elasticidade da demanda e parâmetro de conduta de mercado da NEIO}

Com o lançamento no país dos carros flex-fuel, em 2003, o consumidor ampliou seu poder de escolha, decidindo consumir entre gasolina $\mathrm{C}$ e etanol combustível. Uma pesquisa encomendada ao IBOPE pela União da Indústria da Cana-De-Açúcar — UNICA, em 2006, mostrou que a proporção dos donos de carro flex que optam pelo etanol como combustível principal em São Paulo corresponde a $88 \%$, enquanto no Nordeste são $63 \%$, e no Sul $60 \%$.

\footnotetext{
${ }^{12}$ A alíquota do ICMS era de $25 \%$ sobre o faturamento até 2003, em São Paulo. Em 2004, passou à $12 \%$ (Farina et al. 2010).

${ }^{13}$ A alíquota PIS/COFINS era de $8,2 \%$ para a distribuidora até setembro de 2008 . Em outubro de 2008 , as distribuidoras passaram a recolher $\mathrm{R} \$ 72 / 1000 \mathrm{~L}$ de etanol hidratado (Farina et al. 2010).

${ }^{14} \mathrm{O}$ preço ao produtor de etanol hidratado foi obtido no site do CEPEA ht tp : / / www . cepea . esalq.usp.br/alcool/. As séries apresentadas no site referem-se a valores semanais. Desta série construi-se uma série mensal, estimando-se a média dos valores semanais. Esse preço é transformado em valores reais utilizando como deflator o IGP-DI

${ }^{15}$ Disponível em: http : / / www. sincopetro.org.br/conteudo . aspx ?xmenu=110.

${ }^{16}$ Este curso é um preço médio para a coleta de álcool, considerando um custo médio de transporte de álcool de aproximadamente $400 \mathrm{~km}$
} 
O critério de escolha, em geral, tem sido a comparação entre o preço e a quilometragem rodada, isso porque o menor teor de energia do etanol em relação à gasolina, faz com que a paridade de preços por quilômetro rodado ocorra quando o preço por litro de etanol equivale a aproximadamente $70 \%$ do preço por litro de gasolina (Salvo \& Huse 2011).

Assim sendo, a gasolina $C$ é, supostamente, um produto substituto para o etanol hidratado. Dessa forma, adota-se aqui o preço médio da Gasolina C, para o consumidor, no estado de São Paulo, como uma das variáveis da curva de demanda por etanol hidratado. Esses preços, aqui denominados Pgasol, foram coletados no site da ANP. ${ }^{17}$ Ressalta-se que essa variável será defasada em um período, sendo denominada, portanto, na equação como $\operatorname{Pgasol}_{t-1}$. Essa defasagem no preço da gasolina é necessária dada a possível endogeneidade existente entre os preços do etanol combustível e da gasolina.

No mesmo site, da ANP, estão disponíveis os valores coletados para a série de preço de etanol hidratado - Preço Distribuidora, para o estado de São Paulo, aqui denominada Pdist. Todos os preços são deflacionados pelo IGPDI, para valores em reais de agosto de 2010.

Dados de quantidade vendida pelas distribuidoras de etanol hidratado, $Q$, são obtidos no site da ANP. ${ }^{18}$ Utilizam-se os dados de venda em litros de etanol, para o estado de São Paulo. A variável renda é tomada da série de "Rendimento médio real efetivo das pessoas ocupadas - Região Metropolitana de São Paulo", ${ }^{19}$ do IBGE. Esta variável funciona como deslocadora da curva de demanda, e é utilizada para identificar a curva de oferta, como discutido na seção 3.1. A taxa de desemprego, representada por txdesemp, é a taxa de desemprego para a região metropolitana de São Paulo, do IBGE. As duas últimas variáveis foram adotadas considerando-se o trabalho de Farina et al. (2010), que também utilizaram as duas variáveis na estimação da demanda de etanol. As séries abrangem o período de janeiro de 2003 a maio de 2010.

Genesove \& Mullin (1998) usaram dados trimestrais (ao invés de mensais ou semanais) para evitar tendência de subestimação da elasticidade da demanda. Neste trabalho, optou-se pela utilização dos dados mensais visto que a frequência trimestral levaria a um número muito reduzido de observações, devido aos dados disponíveis.

A forma funcional da demanda, aqui adotada, é: ${ }^{20}$

\footnotetext{
${ }^{17}$ Preços disponíveis em: http://www.anp.gov.br/preco/prc/ Resumo_Mensal_Index.asp.

${ }^{18}$ Dados de vendas disponíveis em: http : / / www . anp.gov.br / ?pg=19241\&m=vendas\& $\mathrm{t} 1=\& \mathrm{t} 2=\mathrm{vendas} \& \mathrm{t} 3=\& \mathrm{t} 4=\& \mathrm{ar}=0 \& \mathrm{ps}=1 \backslash \& \mathrm{cachebust}=1270313218359$. No site estão disponíveis planilhas para download. Escolhe-se a planilha: "Vendas, pelas distribuidoras, dos derivados combustíveis de petróleo (metros cúbicos)". Após aberta a planilha, escolhe-se a un. da federação "São Paulo", e produto "Etanol Hidratado $\left(\mathrm{m}^{3}\right)$ ". Os dados apresentados são em $\mathrm{m}^{3}$, mas foram transformados para litros, na presente aplicação.

${ }^{19}$ Disponível em: https: / / www3 . bcb.gov.br/sgspub/localizarseries/ localizarSeries . do?method=prepararTelaLocalizarSeries Corresponde ao "Rendimento efetivamente recebido do trabalho no mês de referência".

${ }^{20}$ A forma funcional parte de uma especificação geral de demanda: $Q(P)=\beta(\alpha-P)^{y}$ Onde $Q(P)$ é a quantidade demandada de etanol em função de seu preço. $\beta$ mede o tamanho da demanda de mercado, $\alpha$ é a disponibilidade máxima a pagar, e $y$ é o índice de convexidade. Dado o resultado de Genesove \& Mullin (1998) no qual as estimativas NEIO do parâmetro de conduta, para o mercado de açúcar refinado, eram insensíveis à forma de demanda assumida, opta-se no presente trabalho, por utilizar a especificação linear da demanda, em que $y=1$. Assim, especificase a forma funcional linear: $Q(P)=\beta(\alpha-P)+\varepsilon$; Onde $\varepsilon$ é o termo de erro, que representa mudanças proporcionais na demanda, ou as variações de $\beta$.
} 


$$
Q_{t}=\alpha_{0}+\alpha_{1} \text { Pdist }_{t}+\alpha_{2} \text { Pgasol }_{t-1}+\alpha_{3} \text { rend }_{t}+\alpha_{4} \text { txdesemp } t_{t}+\varepsilon_{1}
$$

Em que $\alpha$ são os parâmetros de demanda a serem estimados, sendo $\alpha_{1}$ a elasticidade da demanda, ${ }^{21}$ e a equação estimada é do tipo log-log. ${ }^{22}$

A relação de oferta, ${ }^{23}$ dada por (8), aqui é descrita como

$$
\text { Pdist }=c m g_{t}-\Theta Q_{t} P^{\prime}(Q)
$$

Em que $c m g_{t}$ é o custo marginal do distribuidor no período $t$. Note-se que esse custo marginal - estimado para ser usado no Índice de Lerner elasticidade-ajustado - dado por (12) mostra que tal custo é representado por impostos, frete e preço de etanol ao produtor. Dessa forma, se não há informações sobre esse custo (caso da aplicação da NEIO), pode-se considerar que ele seja subdividido em dois grandes componentes: o preço ao produtor de etanol, Pprod (que representa cerca de $70 \%$ do total desse custo), ${ }^{24}$ e outro componente dado pelos impostos e frete.

A questão que se coloca, como tratado, é que a relação de oferta (15) deve possuir deslocadores da oferta (variáveis exógenas ou pré-determinadas) excluídos da função demanda, para que a curva de demanda seja identificada. Assim, o preço ao produtor que entra na relação de oferta (através do $c m g_{t}$ ) será defasado em um período, Pprod $_{t-1}$, funcionando como variável identificadora da curva da demanda. A defasagem da variável preço de produtor é devida ao processo de formação de preço no elo do distribuidor. No modelo desenvolvido por Barros (1990), com base na existência de defasagem distribuída, a oferta sofre influência do preço observado pelos agentes de mercado no período anterior.

Como o custo marginal é assumido constante, ou seja, não depende da quantidade, não é necessária a variável de interação para a rotação da curva de demanda e consequente identificação do parâmetro de conduta. A forma do custo marginal será então:

$$
c m g_{t}=\gamma_{0}+\gamma_{1} \operatorname{Pprod}_{t-1}
$$

Substituindo esta estrutura de custo marginal e a inclinação da curva de demanda inversa, $P^{\prime}(Q)$, na relação de oferta geral (15), tem-se a relação de oferta específica:

$$
\operatorname{Pdist}_{t}=\gamma_{0}+\gamma_{1} \text { Pprod }_{t-1}-Q_{t} \Theta P^{\prime}(Q)
$$

Uma vez que $P^{\prime}(Q)=\frac{1}{\alpha_{1}}$, tem-se:

$$
\text { Pdist }=\gamma_{0}+\gamma_{1} \text { Prod }_{t-1}-Q_{t} \frac{\Theta}{\alpha_{1}}
$$

$\mathrm{ou}$

\footnotetext{
${ }^{21}$ Lembrando que a elasticidade da demanda estimada, $\alpha_{1}$, é usada no cálculo do índice de Lerner elasticidade-ajustado (ou a medida direta de conduta). Naquela equação essa elasticidade foi denominada $\eta_{P}$ dist

${ }^{22}$ A forma logarítmica foi assumida para obtenção direta da elasticidade da demanda.

${ }^{23}$ A relação de oferta vem da regra de precificação dos modelos de oligopólios, $P+\Theta Q P^{\prime}(Q)=c$.

${ }^{24}$ Para mais detalhes, ver tabelas de custo de distribuidor da Sincopetro http://Www sincopetro.org.br/conteudo. asp? xmenu=110.
} 


$$
\operatorname{Pdist~}_{t}=\gamma_{0}+\gamma_{1} \text { Pprod }_{t-1}+\gamma_{2} Q_{t}+\varepsilon_{2}
$$

Onde $\gamma_{2}=-\frac{\theta}{\alpha_{1}}$, uma vez que ${ }^{25} \Theta P^{\prime}(Q)=\frac{\Theta}{\alpha_{1}}$.

Assim, o sistema de equações a ser estimado é composto pela curva de demanda (14) e a relação de oferta específica (17), e seus respectivos instrumentos.

Como descrito, dada a endogeneidade da variável explicativa, adota-se um modelo estrutural com estimação dos parâmetros via MQ2E. A forma de estimar o presente modelo estrutural por esta técnica é descrita a seguir. O modelo estrutural completo pode ser representado por:

$$
\begin{aligned}
& Q_{d}=f(\text { Pdist }, \text { Pgasol, } \text { renda, } t x \text { desemp })+\varepsilon_{1} \\
& \text { Pdist }=i\left(\text { Pprod }, Q_{d}\right)+\varepsilon_{2}
\end{aligned}
$$

Em que $Q_{d}$ e Pdist são variáveis endógenas, e renda, Pgasol(defasado), txdesemp e Pprod(defasado) são variáveis predeterminadas.

Tabela 2: Descrição das variáveis utilizadas no modelo

\begin{tabular}{ll}
\hline$Q_{D t}$ & Quantidade demandada de etanol hidratado, no período $t$ \\
Pdist $_{t}$ & Preço ao distribuidor de etanol hidratado no período $t$ \\
Pgasol $_{t-1}$ & Preço da gasolina C na bomba, defasado em 1 período \\
renda $_{t}$ & Rendimento médio real efetivo - ocupados - região metropoli- \\
& tana de São Paulo \\
Prod $_{t-1}$ & Preço ao produtor de etanol hidratado, defasado em 1 período \\
txdesemp $_{t}$ & Taxa de desemprego no período $t$ \\
\hline
\end{tabular}

A sazonalidade da demanda de etanol hidratado é pouco acentuada, motivo pelo qual não foram consideradas variáveis dummies para captar esse comportamento no modelo. O maior consumo ocorre no mês de dezembro, mas ele é menos de 3\% maior do que o menor valor - fevereiro, que tem um menor número de dias (conforme ilustrado no Apêndice B, Figura B.1).

A primeira equação de (18) é a demanda, dada por (14), e a segunda equação é a relação de oferta, conforme definida em (17).

Dessa forma, utilizam-se as variáveis pré-determinadas da oferta, para identificar a demanda, no caso Pprod $_{t-1}$.

Para estimar o modelo via mínimos quadrados em dois estágios, parte-se para a relação de oferta $P d i s t_{t}=\gamma_{0}+\gamma_{1}$ Pprod $_{t-1}+\gamma_{2} Q_{t}+\varepsilon_{2}$, substituindo nela a variável $Q_{t}$ pela equação da demanda, resultando:

$$
Q_{t}=\alpha_{0}+\alpha_{1} \text { Pdist }_{t}+\alpha_{2} \text { Pgasol }_{t-1}+\alpha_{3} \text { rend }_{t}+\alpha_{4} \text { txdesemp } t+\varepsilon_{1}
$$

Assim, chega-se à relação de oferta a seguir:

$$
\text { Pdist }_{t}=\beta_{0}+\beta_{1} \text { Pprod }_{t-1}+\beta_{2} \text { Pgasol }_{t-1}+\beta_{3} \text { renda } \text { f }_{t}+\beta_{4} \text { txdesemp }+\varepsilon_{3}
$$

\footnotetext{
${ }^{25}$ Observar que o sinal negativo em $\gamma_{2}=-\frac{\Theta}{\alpha_{1}}$ é dado pela relação de oferta da indústria (15) e nada tem a ver com o sinal de $P^{\prime}(Q)$. da condição de maximização de lucros (igualando custo marginal à receita marginal).
} 
Em que $\varepsilon_{3}$ é o resíduo. Dessa forma, gera-se a variável $P$ dist $\hat{i}_{t}=$ Pdist $_{t}-\varepsilon_{3}$.

A partir daí pode-se estimar a equação da demanda substituindo $P d i s t$, nesta equação, por sua estimativa Pdist:

Dessa forma, obtêm-se parâmetros consistentes para a demanda.

Após estimar a equação da demanda, obtêm-se $\hat{Q}=Q-\varepsilon_{1}$, que é substituído na relação de oferta, gerando estimativa de coeficientes consistentes para a oferta: Pdist $=\gamma_{0}+\gamma_{1}$ Pprod $_{t-1}+\gamma_{2} \hat{Q}_{t}+\varepsilon_{2}$.

Sabendo que o coeficiente $\gamma_{2}=-\frac{\Theta}{\alpha_{1}}$, obtém-se a estimativa NEIO do parâmetro de conduta de mercado, $\Theta$.

Segundo Oczkowski (2003), para avaliar o quão bons são os instrumentos utilizados no modelo, deve-se analisar o R-quadrado da equação do primeiro estágio. Um valor de R-quadrado menor que 0,10 indica que os instrumentos devem ser inapropriados. O autor ainda relata que "outra verificação útil da relevância dos instrumentos é garantir que as estatísticas $\mathrm{F}$ das regressões do primeiro estágio sejam superiores a 10, ver Stock e Watson (2003, cap 10)." trad. de Oczkowski (2003).

Outra alternativa é utilizar o teste de Sargan, que é mais indicado do que os critérios acima mencionados para avaliar a força dos instrumentos utilizados no modelo, para o caso de equações não exatamente identificadas. Esse teste é dado por $\mathrm{NR}^{2}$, ou seja, número de observações multiplicado pelo coeficiente de determinação de uma regressão de mínimos quadrados ordinários dos resíduos obtidos através do método de mínimos quadrados em dos estágios sobre as variáveis exógenas do modelo. A estatística tem distribuição $\chi^{2} \mathrm{com} \mathrm{m}-\mathrm{k}$ graus de liberdade, sendo $\mathrm{m}$ o número de instrumentos e $\mathrm{k}$ o número de variáveis endógenas (número de instrumentos excedentes). A hipótese nula é que todos os instrumentos são válidos. Se rejeitada a hipótese nula, tem-se que pelo menos um dos instrumentos é correlacionado com o termo do erro (Gujarati 2004).

Portanto, a técnica NEIO parte da equação de demanda e da relação de oferta para identificar um parâmetro de conduta de mercado, assumindo-se que custos marginais não são observáveis (Bresnahan 1989). Dessa maneira, percorrendo todo o caminho descrito pelo modelo estrutural, a NEIO estima o parâmetro de conduta de mercado, $\Theta$, sem informações de custos diretamente, como se percebe das equações acima, em que estão presentes apenas variáveis como preços, quantidade, renda e taxa de desemprego.

\section{Resultados}

A presente seção apresenta o resultado da aplicação da metodologia discutida.

\subsection{Equação de Demanda}

No que se refere aos instrumentos utilizados, a estimativa do modelo em dois estágios apresentou um R-quadrado no primeiro estágio de 0,92 e uma estatística $\mathrm{F}$ de 266,23 . Essas estatísticas indicam que o modelo é apropriadamente instrumentado, conforme Oczkowski (2003). O teste de Sargan não se aplica à equação exatamente identificada, como a que está sendo tratada.

Antes de partir para a estimação da demanda propriamente dita, vale uma importante ressalva. Sabe-se que muitas séries de tempo macroeconômicas e financeiras são conhecidas por serem não estacionárias, o que invalida proces- 
sos de estimação que assumem estacionariedade, como os de Mínimos Quadrados Ordinários (MQO). Entretanto, segundo Hsiao (1996), em modelos estruturais a preocupação deve estar em problemas clássicos de identificação e estimação, e não em não estacionariedade e cointegração, visto que certas combinações lineares de séries não estacionárias podem ser estacionárias. Hsiao (1996) demonstra que os estimadores de Mínimos Quadrados em Dois Estágios (MQ2E) são consistentes e possuem boas propriedades estatísticas, mesmo sob condições de variáveis não estacionárias.

Para testar a estacionariedade das séries foi utilizado o teste DF-GLS, cujos resultados são apresentados na Tabela 3. Com exceção do teste do modelo 1 para $Q$, todos os valores obtidos apontam que existe raiz unitária nas séries, sendo pertinente testar cointegração.

A seguir descrevem-se os resultados dos testes de Elliott-Rothenberg-Stock, para raiz unitária, com as séries utilizadas no modelo.

Tabela 3: Resultados dos testes de raiz unitária de ElliottRothenberg-Stock (DF-GLS) para as séries utilizadas no modelo

\begin{tabular}{lrcrc}
\hline Variável & \multicolumn{1}{c}{ Modelo 1 } & Modelo 2 \\
\hline & $\mathrm{P}$ & Estatística DF-GLS & $\mathrm{P}$ & Estatística DF-GLS \\
\hline$Q$ & 0 & $-3,399^{*}$ & 0 & 0,087 \\
Pdist & 0 & $-2,030$ & 0 & $-1,525$ \\
Pgasol & 7 & $-1,882$ & 7 & 0,133 \\
renda & 11 & $-1,291$ & 11 & $-0,083$ \\
txdesemp & 11 & $-1,772$ & 11 & 0,655 \\
Pprod & 0 & $-2,397$ & 0 & $-1,717$ \\
\hline
\end{tabular}

Fonte: Elaboração própria com dados da pesquisa.

Modelo 1: versão com constante e tendência (valores críticos em Elliot et al. 1996).

Modelo 2: versão apenas com constante (valores críticos em Dickey \& Fuller 1979, 1981).

* Significativo ao nível de $1 \%$ de probabilidade. Os outros valores são significativos.

A análise de cointegração, feita utilizando-se a metodologia de Johansen, mostrou, através da estatística traço, que existe um vetor de cointegraçao ao nível de significância de $0,05 \%$ de probabilidade, ou seja, uma relação de equilíbrio de longo prazo entre as variáveis consideradas no modelo de demanda de etanol. O resultado foi robusto, não sendo observada divergência tanto quando se utilizou o modelo com constante dentro do termo de correção de erro, quanto quando se utilizou o modelo com a constante fora do termo de correção de erro ou, ainda, quando se utilizou o modelo incluindo constante fora do termo de correção de erro e tendência dentro do termo de correção de erro. O Apêndice $\mathrm{C}$ traz o resultado dos testes.

Dessa forma, considerando-se a existência do vetor de cointegração, segundo Hsiao (1996), o uso de MQ2E para as séries em nível valida um modelo com estimadores consistentes e boas propriedades estatísticas.

O coeficiente do preço de distribuidor de etanol, $\alpha_{1}=-0,64465$, uma vez que a equação está na forma logarítmica (modelo log-log), é a elasticidade da demanda de etanol hidratado, para o estado de São Paulo. Essa elastici- 
Tabela 4: Resultado da estimação da equação de demanda do elo da distribuição de etanol

\begin{tabular}{lcc}
\hline Variável & Valor do coeficiente & Estatística $t$ \\
\hline Constante & $-0,032160419$ & $-0,00661$ \\
Pdist $_{t}$ & $-0,644651818$ & $-2,30427$ \\
Pgasol $_{t-1}$ & $-0,874658175$ & $-1,09759$ \\
renda $_{t}$ & 1,589040642 & 2,65649 \\
txdesemp $_{t}$ & $-2,025382647$ & $-6,64069$ \\
\hline
\end{tabular}

Fonte: resultado da regressão - Software Rats.

dade reflete o fato de que um aumento de $1 \%$ no preço ao distribuidor reduz a quantidade demandada em aproximadamente $0,64 \%$. O sinal positivo do coeficiente da renda indica que o aumento na renda aumenta a demanda de etanol, e o sinal negativo do coeficiente da taxa de desemprego indica que o aumento nesta reduz a demanda por etanol. Esses sinais parecem indicar que o etanol é tido como um bem normal, para o consumidor. O coeficiente do preço da gasolina apresentou-se estatisticamente não diferente de zero, ao contrário dos associados às demais variáveis.

\subsection{Medida de conduta direta da distribuição de etanol}

A Tabela 5 e a Figura 1 apresentam o Índice de Lerner elasticidade-ajustado no tempo. Esse índice foi calculado a partir da estimação da série de custo marginal ${ }^{26}$ do distribuidor dado pela incidência dos impostos, pelo frete e pelo preço ao produtor, conforme (12). Após aferir-se o custo marginal, $\mathrm{cmg}$, e tendo o valor da elasticidade da demanda estimada, parte-se para a estimação dos valores da Tabela 5, pela equação do índice de Lerner elasticidadeajustado (equação 13).

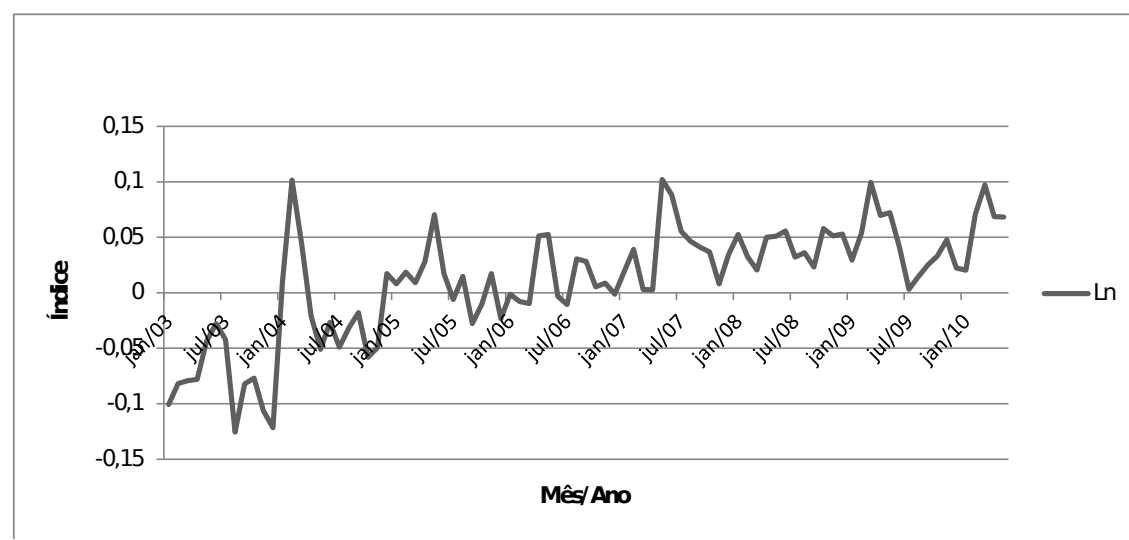

Figura 1: Índice de Lerner elasticidade-ajustado para o elo distribuidor

Pelas análises da tabela e do gráfico, pode-se perceber uma tendência ao aumento do Índice de Lerner elasticidade-ajustado no tempo. O efeito dessa va-

\footnotetext{
${ }^{26}$ A Tabela com a descrição de cada elemento dos custos marginais estimados encontra-se no Apêndice A
} 
Tabela 5: Índice de Lerner elasticidade-ajustado no tempo - $\left(L \eta_{\text {dist }}\right)$

\begin{tabular}{cccccccc}
\hline Data & $\ln$ & Data & $\ln$ & Data & $\ln$ & Data & $\ln$ \\
\hline Jan-03 & $-0,10073$ & Dec-04 & 0,017241 & Nov-06 & 0,008705 & Oct-08 & 0,057858 \\
Feb-03 & $-0,08182$ & Jan-05 & 0,008098 & Dec-06 & $-0,00119$ & Nov-08 & 0,051254 \\
Mar-03 & $-0,07916$ & Feb-05 & 0,018522 & Jan-07 & 0,019351 & Dec-08 & 0,052844 \\
Apr-03 & $-0,0779$ & Mar-05 & 0,009148 & Feb-07 & 0,03923 & Jan-09 & 0,029533 \\
May-03 & $-0,04389$ & Apr-05 & 0,028082 & Mar-07 & 0,002953 & Feb-09 & 0,053955 \\
Jun-03 & $-0,02778$ & May-05 & 0,070374 & Apr-07 & 0,002588 & Mar-09 & 0,099558 \\
Jul-03 & $-0,04219$ & Jun-05 & 0,017356 & May-07 & 0,102139 & Apr-09 & 0,069776 \\
Aug-03 & $-0,12563$ & Jul-05 & $-0,00617$ & Jun-07 & 0,088321 & May-09 & 0,072273 \\
Sep-03 & $-0,08202$ & Aug-05 & 0,014809 & Jul-07 & 0,055398 & Jun-09 & 0,041321 \\
Oct-03 & $-0,07689$ & Sep-05 & $-0,0278$ & Aug-07 & 0,046385 & Jul-09 & 0,003172 \\
Nov-03 & $-0,10651$ & Oct-05 & $-0,01013$ & Sep-07 & 0,041093 & Aug-09 & 0,014602 \\
Dec-03 & $-0,12157$ & Nov-05 & 0,017278 & Oct-07 & 0,036871 & Sep-09 & 0,025131 \\
Jan-04 & 0,009928 & Dec-05 & $-0,02324$ & Nov-07 & 0,008095 & Oct-09 & 0,03313 \\
Feb-04 & 0,101526 & Jan-06 & $-0,00122$ & Dec-07 & 0,034506 & Nov-09 & 0,047733 \\
Mar-04 & 0,045003 & Feb-06 & $-0,00783$ & Jan-08 & 0,052641 & Dec-09 & 0,022408 \\
Apr-04 & $-0,02082$ & Mar-06 & $-0,00969$ & Feb-08 & 0,032312 & Jan-10 & 0,020341 \\
May-04 & $-0,05101$ & Apr-06 & 0,051232 & Mar-08 & 0,020485 & Feb-10 & 0,070977 \\
Jun-04 & $-0,02665$ & May-06 & 0,052642 & Apr-08 & 0,050036 & Mar-10 & 0,09719 \\
Jul-04 & $-0,04897$ & Jun-06 & $-0,00315$ & May-08 & 0,050924 & Apr-10 & 0,068698 \\
Aug-04 & $-0,03141$ & Jul-06 & $-0,01056$ & Jun-08 & 0,055685 & May-10 & 0,068295 \\
Sep-04 & $-0,01797$ & Aug-06 & 0,030571 & Jul-08 & 0,032134 & & \\
Oct-04 & $-0,05807$ & Sep-06 & 0,028294 & Aug-08 & 0,036092 & & \\
Nov-04 & $-0,04932$ & Oct-06 & 0,005346 & Sep-08 & 0,023207 & & \\
\hline Fonte: Ela & Eboç0 propran & & & \\
\hline
\end{tabular}

Fonte: Elaboração própria com resultados da pesquisa.

riação no tempo, de forma mais clara, pode ser visto na Tabela 6, que mostra esse índice agregado ano a ano.

Tabela 6: Medida direta anual de $\Theta$ - elo da distribuição

\begin{tabular}{cc}
\hline ANO & Médias anuais da medida direta de $\Theta$ \\
\hline 2003 & $-0,080507646$ \\
2004 & $-0,010876683$ \\
2005 & 0,009693591 \\
2006 & 0,011928719 \\
2007 & 0,039744237 \\
2008 & 0,042955805 \\
2009 & 0,042716128 \\
2010 & 0,065100155 \\
\hline \multicolumn{2}{l}{ Fonte: Elaboração própria com resultados da pesquisa. }
\end{tabular}

Nas Tabelas 5 e 6, percebe-se que para diversos períodos o parâmetro esteve negativo. Os valores negativos mostram períodos em que os distribuidores operaram com margem negativa. Segundo Farina et al. (2010, p. 258, nota de rodapé 12): "Uma possível explicação para a presença de margens negativas reside no fato do setor sofrer forte sonegação de impostos, que comprime as margens dos agentes idôneos". Ou também reflete o fato de que uma parte dos agentes trabalha com margens positivas, justamente por não recolherem os impostos, mas esse fato não é captado nos cálculos, visto que se considerou que todos os agentes recolheriam os impostos devidos. Lopes et al. (2011), analisando as características das transações entre distribuidoras e postos re- 
vendedores mostram que existem cinco práticas informais que ocorrem com mais frequência no mercado de etanol, dentre elas está a "venda clandestina (venda direta das usinas às distribuidoras ou aos postos, sem recolhimento de tributos)" e o "contrabando (compra de álcool num estado com alíquota de ICMS menor e simulação de venda para estados com alíquota maior)". E sobre a sonegação, por parte das distribuidoras apontam que o governo e algumas distribuidoras ligadas a sindicatos de classe tentaram transferir os tributos do etanol para as usinas "devido à grande quantidade de distribuidoras que sonega impostos (PIS e COFINS)". Concluem que a informalidade na distribuição de etanol reduz a margem de lucro, pois

"os agentes que trabalham de maneira ilegal conseguem vender o etanol hidratado com preço reduzido; com isso, para conseguirem concorrer nesse mercado, os agentes que trabalham legalmente são obrigados a diminuir suas margens de lucro obtidas com o combustível para acompanhar o preço." (Lopes et al. 2011).

Ainda em relação aos valores do parâmetro $\Theta$, percebe-se uma tendência de aumento no tempo, mostrando que o poder de mercado, ainda que pequeno, segundo o valor desse parâmetro, ${ }^{27}$ parece apresentar uma tendência de elevação nos anos recentes.

O valor de $\Theta$ usado como medida direta é a média global do Índice de Lerner elasticidade-ajustado para todos os anos analisados, sendo este valor igual a 0,011 . Como se percebe, um valor global baixo, indicando pouco exercício de poder de mercado (estrutura bem próxima à concorrência perfeita, em que $\Theta=0$ ) no elo da distribuição de etanol hidratado, se considerado o período de janeiro de 2003 a maio de 2010 como um todo.

\subsection{Estimativa segundo Modelo estrutural NEIO}

Seguindo a estimação da relação de oferta dada por:

$$
\text { Pdist }_{t}=\gamma_{0}+\gamma_{1} \text { Prod }_{t-1}+\gamma_{2} Q_{t}+\varepsilon_{2}
$$

Estimam-se os resultados expostos na Tabela 7 .

Assim, dado que $\gamma_{2}=-\frac{\Theta}{\alpha_{1}}$, tem-se $\Theta=-\gamma_{2} * \alpha_{1}$.

Então, $\Theta=-\gamma_{2} * \alpha_{1}=-(0,0444554945) *(-0,644651818)$ e, tem-se um valor da estimativa da conduta de mercado, da NEIO, de aproximadamente ${ }^{28}$ $\Theta=0,028$.

\section{Conclusões}

O trabalho buscou estimar um parâmetro de conduta de mercado para o elo da distribuição de etanol, no período entre 2003 e início de 2010, para analisar

\footnotetext{
${ }^{27} \mathrm{O}$ parâmetro de conduta varia de zero a um, sendo zero quando um mercado em concorrência perfeita e um quando um mercado monopolista puro. Ou ainda $\frac{1}{N}$, sendo $N$ o número de firmas na indústria, quando se trata de um modelo de Cournot. Na realidade, os autores reportam os valores do parâmetro, indicando como o mercado se comporta. Se um valor próximo à zero está mais para um ambiente concorrencial, em que não se pratica poder de mercado. Se mais próximo à um, indica-se um mercado em que o poder de mercado está sendo exercido.

${ }^{28}$ Desvio padrão de $\Theta$, estimado pelo Método Delta (baseado na expansão de Taylor de primeira ordem) foi de $s(\Theta)=0,0144$
} 
Tabela 7: Resultados da regressão da relação de oferta da distribuição

\begin{tabular}{lcc}
\hline Variável & Valor do coeficiente & Estatística $t$ \\
\hline constante & 0,0568189870 & 0,88194 \\
Pprod $_{t-1}$ & 0,8516787116 & 30,39484 \\
$Q_{t}$ & 0,0444554945 & 3,94534 \\
\hline Fonte: Resultado da estimação - Software Rats. \\
Nota: Oresultado do teste de Sargan (5, 376190) indica \\
que, considerando-se o nível de significância de 0,05 de \\
probabilidade, o termo de erro é não correlacionado com \\
os instrumentos.
\end{tabular}

a questão da existência e do grau de poder de mercado neste elo da cadeia de etanol no estado de São Paulo, tomado como uma proxy para o Brasil.

Também procurou comparar os valores do parâmetro de conduta $(\Theta)$, através de duas metodologias: a da Nova Organização Industrial Empírica (NEIO), que estima a conduta de mercado sem informações completas de custo; e uma metodologia alternativa, na qual se estimaram as informações de custos necessárias à construção do parâmetro de conduta em questão, denominado " $m e$ dida direta de conduta". Este último usado para testar a eficiência da metodologia NEIO em estimar o parâmetro de conduta.

Os resultados encontrados no presente trabalho reforçam as conclusões de Genesove \& Mullin (1998), para o mercado aqui analisado, de que a NEIO (Nova Organização Industrial Empírica) é eficiente em estimar a conduta de mercado, sem informações completas de custos.

A análise dos valores encontrados indica que a medida de conduta de inferência direta, $\Theta=0,011$, rejeita a concorrência perfeita (pois mesmo sendo um valor bem pequeno é diferente de zero) e o monopólio (pois também está bem longe de um). Da mesma forma, a estimativa NEIO da conduta de inferência indireta, $\Theta=0,028$, rejeita tanto a concorrência perfeita, quanto o monopólio. Os valores baixos da medida direta e da estimativa NEIO da conduta indicam que o elo da distribuição de etanol, apesar de relativamente concentrado (caracterizado como um oligopólio com franja competitiva, segundo Neves \& Conejero 2010), apresentou baixo exercício de poder de mercado para o período entre janeiro de 2003 e maio de 2010 como um todo.

Contudo, ao se pensar sobre a relação entre aumento da concentração e poder de mercado, observou-se que a evolução do cálculo do parâmetro de conduta anualmente apresenta um aumento gradativo do parâmetro de conduta $(\Theta)$ condizente com o aumento dos índices de concentração de mercado.

\section{Referências Bibliográficas}

Barros, G. S. A. C. (1990), 'Transmissão de preços pela central de abastecimento de são paulo, brasil', Revista Brasileira de Economia 44(1), 5-20.

Bresnahan, T. F. (1982), The oligopoly solution concept is identified, Vol. 19, Economics Letters.

Bresnahan, T. F. (1989), Empirical studies of industries with market power, Vol. 2, amsterdam: north-holland edn, Handbook of industrial organization. 
Church, J. \& Ware, R. (2000), 'Industrial organization: a strategic approach', Irwin McGrawHill pp. 423-456.

Daskin, A. J. (1991), 'Deadweight loss in oligopoly: A new approach', Southern Economic Journal 58(1), 171-185.

Dickey, D. A. \& Fuller, W. A. (1979), 'Distribution of the estimator for autoregressive time series with a unit root', Journal of the American Statistical Association $74,427-431$.

Dickey, D. A. \& Fuller, W. A. (1981), 'Likelihood ratio statistics for autoregressive time series with a unit root', Econometrica 49, 1057-1072.

Elliot, G., Rothenberg, T. J. \& Stock, J. H. (1996), 'Efficient tests for an autoregressive unit root', Econometrica 64, 813-836.

Farina, E. M. M. Q., Viegas, C. A. S., Pereda, P. \& Garcia, C. (2010), Mercado e Concorrênciado Etanol, Editora LUC, chapter Etanol e Bioeletricidade: A cana de açúcar no futuro da matriz energética, pp. 226-311.

Genesove, D. \& Mullin, W. (1998), 'Testing static oligopoly models: Conduct and cost in the sugar industry. 1890-1914.', Rand Journal of Economics 29(2), 355-377.

Gujarati, D. N. (2004), Basic econometrics, United States Military Academy, West Point (Mc Graw Hill).

Hsiao, C. (1996), 'Statistical properties of the two-stage least squares estimator under cointegration', The Review of Economic Studies 64(3), 385-398.

Lopes, M. B., Silva, A. L. d. \& Paulillo, L. F. (2011), 'Características das transações do etanol carburante entre distribuidoras e revendedores', Gest. Prod. 18(2).

URL: $\quad h t t p: / / w w w . s c i e l o . b r / s c i e l o . p h p ? s c r i p t=s c i \_a r t t e x t E p i d=S 0104-$ 530X2011000200008Elng=enEnrm=iso Acesso em 05 Dez. 2012.

Neves, M. F. \& Conejero, M. A. (2010), Estratégias para a cana no Brasil, Atlas.

Oczkowski, E. (2003), 'Two-stage least squares (2sls) and structural equation models (sem)..'

URL: http://csusap.csu.edu.au/ẽoczkows/home.htm\#2sls Acesso em: 10 jun.2010

Salvo, A. \& Huse, C. (2011), 'Is arbitrage tying the price of ethanol to that of gasoline? evidence from the uptake of flexible-fuel technology', Energy Journal 32, 119-148.

Steen, F. \& Salvanes, K. G. (1999), 'Testing for market power using a dynamic oligopoly model', International Journal of Industrial Organization 17(2), 147177.

Zeidan, R. \& Resende, M. (2009), 'Measuring market conduct in the brazilian cement industry: A dynamic econometric investigation', Review of Industrial Organization 34(3), 231-244.

URL: http://ideas.repec.org/p/eui/euiwps/eco2005-13.html Acesso em: 25 maio 2010. 


\section{Apêndice A Custos marginais}

A Tabela A.1 traz os dados das variáveis utilizadas para o cálculo do custo marginal, e os valores encontrados para o mesmo. Na segunda coluna estão os preços ao distribuidor de etanol hidratado, no estado de São Paulo, coletados no site da ANP. A terceira coluna mostra a incidência do imposto ICMS estadual sobre o preço ao distribuidor. Até dezembro de 2003, esse imposto era de $25 \%$ sobre o preço ao distribuidor, passando a $12 \%$ a partir de 2004 , no estado de São Paulo. A quarta coluna mostra a incidência do imposto PIS/COFINS, que era de $8,2 \%$ para o distribuidor, entre janeiro de 2003 e setembro de 2008, passando a $\mathrm{R} \$ 0,072$ /L a partir de outubro de 2008. A quinta coluna se refere à logística, ou o frete. Como discutido, a Sincopetro divulga semanalmente um custo de frete estimado entre as usinas e distribuidoras, e baseado nessas estimativas, emprega-se o valor médio de $\mathrm{R} \$ 0,05 / \mathrm{L}$ para o custo do frete. A sexta coluna é o preço ao produtor, que como visto representa parcela significativa do custo da distribuidora. Esse preço foi coletado, conforme visto, no site do CEPEA. Por fim, a sétima coluna é a soma da terceira à sexta coluna, que dá o valor estimado do custo marginal.

Tabela A.1: Estimação do custo marginal do elo da distribuição

\begin{tabular}{cllllll}
\hline Data & Pdist & ICMS & PIS/COFINS & Frete & Pprod & Cmg \\
\hline Jan-03 & 1,044 & 0,261 & 0,085608 & 0,05 & 0,81052 & 1,207128 \\
Feb-03 & 1,158 & 0,2895 & 0,094956 & 0,05 & 0,870525 & 1,304981 \\
Mar-03 & 1,166 & 0,2915 & 0,095612 & 0,05 & 0,872075 & 1,309187 \\
Apr-03 & 1,129 & 0,28225 & 0,092578 & 0,05 & 0,8406 & 1,265428 \\
May-03 & 1,078 & 0,2695 & 0,088396 & 0,05 & 0,7435 & 1,151396 \\
Jun-03 & 0,866 & 0,2165 & 0,071012 & 0,05 & 0,5658 & 0,903312 \\
Jul-03 & 0,725 & 0,18125 & 0,05945 & 0,05 & 0,48175 & 0,77245 \\
Aug-03 & 0,757 & 0,18925 & 0,062074 & 0,05 & 0,6032 & 0,904524 \\
Sep-03 & 0,786 & 0,1965 & 0,064452 & 0,05 & 0,57505 & 0,886002 \\
Oct-03 & 0,734 & 0,1835 & 0,060188 & 0,05 & 0,52786 & 0,821548 \\
Nov-03 & 0,73 & 0,1825 & 0,05986 & 0,05 & 0,55825 & 0,85061 \\
Dec-03 & 0,771 & 0,19275 & 0,063222 & 0,05 & 0,610425 & 0,916397 \\
Jan-04 & 0,777 & 0,09324 & 0,063714 & 0,05 & 0,55808 & 0,765034 \\
Feb-04 & 0,677 & 0,08124 & 0,055514 & 0,05 & 0,383625 & 0,570379 \\
Mar-04 & 0,533 & 0,06396 & 0,043706 & 0,05 & 0,338125 & 0,495791 \\
Apr-04 & 0,563 & 0,06756 & 0,046166 & 0,05 & 0,41746 & 0,581186 \\
May-04 & 0,6 & 0,072 & 0,0492 & 0,05 & 0,476275 & 0,647475 \\
Jun-04 & 0,699 & 0,08388 & 0,057318 & 0,05 & 0,5367 & 0,727898 \\
Jul-04 & 0,735 & 0,0882 & 0,06027 & 0,05 & 0,59236 & 0,79083 \\
Aug-04 & 0,83 & 0,0996 & 0,06806 & 0,05 & 0,652775 & 0,870435 \\
Sep-04 & 0,851 & 0,10212 & 0,069782 & 0,05 & 0,652825 & 0,874727 \\
Oct-04 & 0,931 & 0,11172 & 0,076342 & 0,05 & 0,7768 & 1,014862 \\
Nov-04 & 1,016 & 0,12192 & 0,083312 & 0,05 & 0,8385 & 1,093732 \\
Dec-04 & 1,059 & 0,12708 & 0,086838 & 0,05 & 0,76676 & 1,030678 \\
Jan-05 & 1,037 & 0,12444 & 0,085034 & 0,05 & 0,7645 & 1,023974 \\
Feb-05 & 1,06 & 0,1272 & 0,08692 & 0,05 & 0,765425 & 1,029545 \\
Mar-05 & 1,05 & 0,126 & 0,0861 & 0,05 & 0,773 & 1,0351 \\
Apr-05 & 1,05 & 0,126 & 0,0861 & 0,05 & 0,74216 & 1,00426 \\
May-05 & 0,918 & 0,11016 & 0,075276 & 0,05 & 0,58235 & 0,817786 \\
Jun-05 & 0,822 & 0,09864 & 0,067404 & 0,05 & 0,583825 & 0,799869 \\
\hline
\end{tabular}


Tabela A.1: Estimação do custo marginal do elo da distribuição (continuação)

\begin{tabular}{|c|c|c|c|c|c|c|}
\hline Data & Pdist & ICMS & PIS/COFINS & Frete & Pprod & $\mathrm{Cmg}$ \\
\hline Jul-05 & 0,892 & 0,10704 & 0,073144 & 0,05 & 0,67036 & 0,900544 \\
\hline Aug-05 & 0,913 & 0,10956 & 0,074866 & 0,05 & 0,6576 & 0,892026 \\
\hline Sep-05 & 0,924 & 0,11088 & 0,075768 & 0,05 & 0,7272 & 0,963848 \\
\hline Oct- 05 & 1,074 & 0,12888 & 0,088068 & 0,05 & 0,823925 & 1,090873 \\
\hline Nov-05 & 1,118 & 0,13416 & 0,091676 & 0,05 & 0,8122 & 1,088036 \\
\hline Dec-05 & 1,2 & 0,144 & 0,0984 & 0,05 & 0,95086 & 1,24326 \\
\hline Jan-06 & 1,338 & 0,16056 & 0,109716 & 0,05 & 1,02025 & 1,340526 \\
\hline Feb-06 & 1,382 & 0,16584 & 0,113324 & 0,05 & 1,069625 & 1,398789 \\
\hline Mar-06 & 1,557 & 0,18684 & 0,127674 & 0,05 & 1,2159 & 1,580414 \\
\hline Apr-06 & 1,541 & 0,18492 & 0,126362 & 0,05 & 1,05725 & 1,418532 \\
\hline May-06 & 1,253 & 0,15036 & 0,102746 & 0,05 & 0,847575 & 1,150681 \\
\hline Jun-06 & 1,128 & 0,13536 & 0,092496 & 0,05 & 0,85566 & 1,133516 \\
\hline Jul-06 & 1,17 & 0,1404 & 0,09594 & 0,05 & 0,902825 & 1,189165 \\
\hline Aug-06 & 1,169 & 0,14028 & 0,095858 & 0,05 & 0,827425 & 1,113563 \\
\hline Sep-06 & 1,073 & 0,12876 & 0,087986 & 0,05 & 0,75916 & 1,025906 \\
\hline Oct-06 & 1,025 & 0,123 & 0,08405 & 0,05 & 0,75945 & 1,0165 \\
\hline Nov-06 & 1,024 & 0,12288 & 0,083968 & 0,05 & 0,753325 & 1,010173 \\
\hline Dec-06 & 1,042 & 0,12504 & 0,085444 & 0,05 & 0,78344 & 1,043924 \\
\hline Jan-07 & 1,172 & 0,14064 & 0,096104 & 0,05 & 0,850075 & 1,136819 \\
\hline Feb-07 & 1,161 & 0,13932 & 0,095202 & 0,05 & 0,805825 & 1,090347 \\
\hline Mar-07 & 1,155 & 0,1386 & 0,09471 & 0,05 & 0,8664 & 1,14971 \\
\hline Apr-07 & 1,251 & 0,15012 & 0,102582 & 0,05 & 0,943275 & 1,245977 \\
\hline May-07 & 1,214 & 0,14568 & 0,099548 & 0,05 & 0,726425 & 1,021653 \\
\hline Jun-07 & 0,965 & 0,1158 & 0,07913 & 0,05 & 0,58786 & 0,83279 \\
\hline Jul-07 & 0,891 & 0,10692 & 0,073062 & 0,05 & 0,58445 & 0,814432 \\
\hline Aug-07 & 0,87 & 0,1044 & 0,07134 & 0,05 & 0,58166 & 0,8074 \\
\hline Sep-07 & 0,859 & 0,10308 & 0,070438 & 0,05 & 0,580725 & 0,804243 \\
\hline Oct- -07 & 0,851 & 0,10212 & 0,069782 & 0,05 & 0,580425 & 0,802327 \\
\hline Nov-07 & 0,981 & 0,11772 & 0,080442 & 0,05 & 0,72052 & 0,968682 \\
\hline Dec-07 & 1,072 & 0,12864 & 0,087904 & 0,05 & 0,748075 & 1,014619 \\
\hline Jan-08 & 1,054 & 0,12648 & 0,086428 & 0,05 & 0,705025 & 0,967933 \\
\hline Feb-08 & 1,013 & 0,12156 & 0,083066 & 0,05 & 0,7076 & 0,962226 \\
\hline Mar-08 & 1,051 & 0,12612 & 0,086182 & 0,05 & 0,7553 & 1,017602 \\
\hline Apr-08 & 1,056 & 0,12672 & 0,086592 & 0,05 & 0,710725 & 0,974037 \\
\hline May-08 & 1,046 & 0,12552 & 0,085772 & 0,05 & 0,70208 & 0,963372 \\
\hline Jun-08 & 1,009 & 0,12108 & 0,082738 & 0,05 & 0,668025 & 0,921843 \\
\hline Jul-08 & 1,029 & 0,12348 & 0,084378 & 0,05 & 0,71985 & 0,977708 \\
\hline Aug-08 & 1,033 & 0,12396 & 0,084706 & 0,05 & 0,7165 & 0,975166 \\
\hline Sep-08 & 1,052 & 0,12624 & 0,086264 & 0,05 & 0,751625 & 1,014129 \\
\hline Oct- 08 & 1,081 & 0,12972 & 0,072 & 0,05 & 0,73226 & 0,98398 \\
\hline Nov-08 & 1,064 & 0,12768 & 0,072 & 0,05 & 0,729725 & 0,979405 \\
\hline Dec-08 & 1,077 & 0,12924 & 0,072 & 0,05 & 0,737475 & 0,988715 \\
\hline
\end{tabular}


Tabela A.1: Estimação do custo marginal do elo da distribuição (continuação)

\begin{tabular}{cllccll}
\hline Data & Pdist & \multicolumn{1}{c}{ ICMS } & PIS/COFINS & Frete & \multicolumn{1}{c}{ Pprod } & \multicolumn{1}{c}{ Cmg } \\
\hline Jan-09 & 1,084 & 0,13008 & 0,072 & 0,05 & 0,78226 & 1,03434 \\
Feb-09 & 1,109 & 0,13308 & 0,072 & 0,05 & 0,7611 & 1,01618 \\
Mar-09 & 1,066 & 0,12792 & 0,072 & 0,05 & 0,65145 & 0,90137 \\
Apr-09 & 0,959 & 0,11508 & 0,072 & 0,05 & 0,61812 & 0,8552 \\
May-09 & 0,921 & 0,11052 & 0,072 & 0,05 & 0,585225 & 0,817745 \\
Jun-09 & 0,893 & 0,10716 & 0,072 & 0,05 & 0,6066 & 0,83576 \\
Jul-09 & 0,951 & 0,11412 & 0,072 & 0,05 & 0,7102 & 0,94632 \\
Aug-09 & 0,99 & 0,1188 & 0,072 & 0,05 & 0,726775 & 0,967575 \\
Sep-09 & 1,088 & 0,13056 & 0,072 & 0,05 & 0,793025 & 1,045585 \\
Oct-09 & 1,271 & 0,15252 & 0,072 & 0,05 & 0,93116 & 1,20568 \\
Nov-09 & 1,318 & 0,15816 & 0,072 & 0,05 & 0,94025 & 1,22041 \\
Dec-09 & 1,355 & 0,1626 & 0,072 & 0,05 & 1,0233 & 1,3079 \\
Jan-10 & 1,545 & 0,1854 & 0,072 & 0,05 & 1,18885 & 1,49625 \\
Feb-10 & 1,578 & 0,18936 & 0,072 & 0,05 & 1,0929 & 1,40426 \\
Mar-10 & 1,31 & 0,1572 & 0,072 & 0,05 & 0,8333 & 1,1125 \\
Apr-10 & 1,197 & 0,14364 & 0,072 & 0,05 & 0,8038 & 1,06944 \\
May-10 & 1,09 & 0,1308 & 0,072 & 0,05 & 0,721725 & 0,974525 \\
\hline
\end{tabular}

\section{Apêndice B Sazonalidade da demanda}

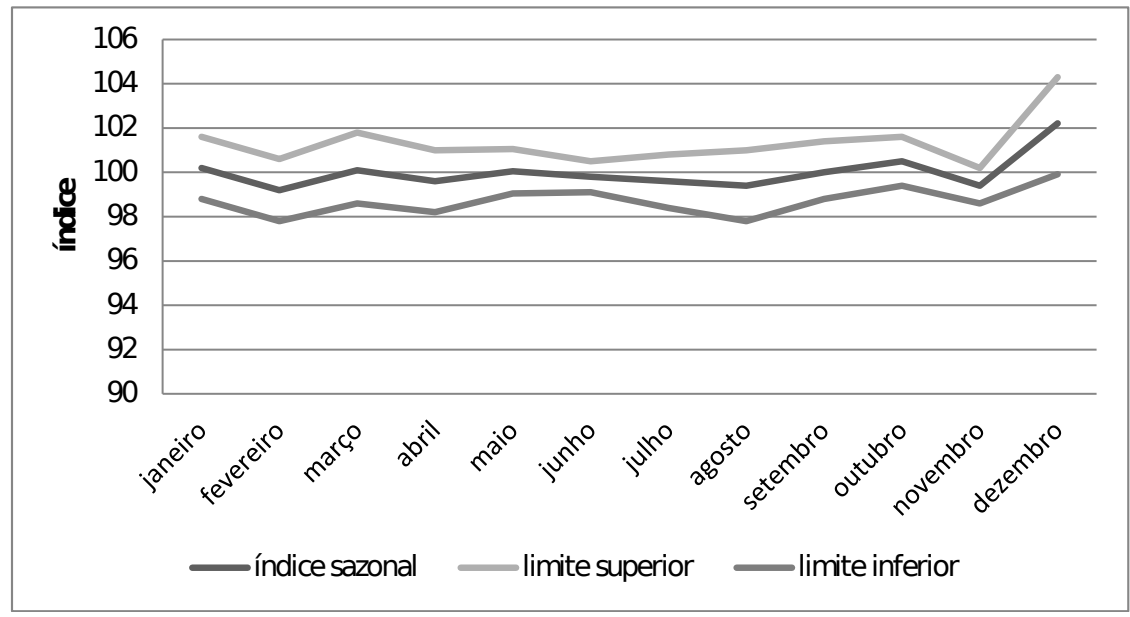

Obs. 1: As linhas laterais indicam a dispersão dos dados em dado mês dos diferentes anos considerados na análise.

Obs. 2: Dados utilizados na análise abrangendo o período janeiro de 2003 a dezembro de 2009.

Figura B.1: Variação sazonal do consumo de etanol hidratado 


\section{Apêndice C Resultados dos testes de cointegraçao de Johansen}

Tabela C.1: Resultados dos testes de co-integraçao de Johansen

\begin{tabular}{cccc}
\hline Hipótese nula & Hipótese alternativa & Estatística & Nível de significância \\
\hline \multicolumn{4}{c}{ Modelo com constante fora do termo de correção de erro } \\
\hline$r \leq 4$ & $r>4$ & 1,269 & 0,26 \\
$r \leq 3$ & $r>3$ & 4,134 & 0,887 \\
$r \leq 2$ & $r>2$ & 14,157 & 0,832 \\
$r \leq 1$ & $r>1$ & 28,865 & 0,775 \\
$r=0$ & $r>0$ & 69,542 & 0,051 \\
\hline \multicolumn{4}{c}{ Modelo com constante no termo de correção de erro } \\
\hline$r \leq 4$ & $r>4$ & 2,83 & 0,62 \\
$r \leq 3$ & $r>3$ & 7,496 & 0,859 \\
$r \leq 2$ & $r>2$ & 20,846 & 0,674 \\
$r \leq 1$ & $r>1$ & 36,252 & 0,665 \\
$r=0$ & $r>0$ & 77,338 & 0,045 \\
\hline Modelo com constante fora do termo de correção de erro e tendência dentro do \\
termo de correção de erro \\
\hline$r \leq 4$ & $r>4$ & 2,722 & 0,895 \\
$r \leq 3$ & $r>3$ & 11,224 & 0,858 \\
$r \leq 2$ & $r>2$ & 25,854 & 0,746 \\
$r \leq 1$ & $r>1$ & 55,579 & 0,205 \\
$r=0$ & $r>0$ & 97,665 & 0,009 \\
\hline
\end{tabular}

Modelos ajustados com uma defasagem conforme indicavam os critérios de Akaike e

Schuarz na versão multiequacional. 